\title{
Effect of Melting Interruption on Composition and Microstructure of BT22 Ingot in VAR
}

\author{
Zhengli Hua*, Wenzhong Luo, Tao He, Qiang Lei, Longzhou Wang, Xianghong Liu \\ Western Superconducting Technologies Co., Ltd., Xi'an 710018, China
}

\begin{abstract}
BT22 ingot was remelted by vacuum arc remelting (VAR) furnace with a melting rate of $20 \mathrm{~kg} / \mathrm{min}$. The power of VAR was interrupted for five minutes when the weight of the remelted ingot is approximately $4000 \mathrm{~kg}$. The melting process was then resumed at the same melting rate after the five minutes interruption. Optical microscopy (OM), inductively coupled plasma-mass spectrometry (ICP-MS) and electron probe micro analyzer (EPMA) were utilized to analyze the microstructure, composition and distribution of elements. No significant microstructural difference was oberved at the remelting interrupted region. The variation of $\mathrm{Al}, \mathrm{Mo}, \mathrm{V}, \mathrm{Cr}, \mathrm{Fe}$ contents between the melting interruption region and normal region is within 0.23 wt $\%$. The distribution of elements in equiaxed grains of the melting interruption region and the normal regions were compared by EPMA analysis. The contents of $\mathrm{Al}, \mathrm{V}, \mathrm{Fe}$ and $\mathrm{Cr}$ increase from the center of equiaxed grains to their grain boundaries. The content of Mo decreases from the center of equiaxed grains to their grain boundaries. The trend of element content in the normal region is similar to that of the melting interrupted region.
\end{abstract}

Key words: BT22; ingot; composition; microstructure

Corresponding author: Zhengli Hua, Engineer, Western Superconducting Technologies Co., Ltd., Xi'an 710018, China, Tel:0086-29-86538751, E-mail: huazhenglihzl@163.com

\section{Introduction}

Vacuum arc remelting (VAR) is the main production method of titanium and titanium alloy ingots. According to the characteristics of VAR melting and the theory of grain segregation, the level of composition segregation increases correspondingly with the increase of the ingot diameter ${ }^{[1-4]}$. The specified composition of BT22 titanium alloy is Ti-5Al-5Mo-5V-1Cr-1Fe, with a weight percentage of alloying elements up to $17 \%$. Easy segregation of Mo, Fe, and $\mathrm{Cr}$ makes composition and microstructure control even more challenge. During the remelting process, occasional metling interruption happens due to the influence of various external factors. The current research takes BT22 titanium alloy as an example to understand the influence of melting interruption on microstructure and chemical composition of ingots.

\section{Experiment}

A BT22 titanium alloy electrode with a weight of $5000 \mathrm{~kg}$ was prepared by pressing and melting for three times in an $8 \mathrm{~T}$ VAR furnace. The diameters of crucible from the first melting to last melting are $\Phi 560 \mathrm{~mm}, \Phi 640 \mathrm{~mm}$ and $\Phi 720 \mathrm{~mm}$, respectively. During the last melting process, the melting rate was set as $20 \mathrm{~kg} / \mathrm{min}$. When the weight of the ingot reaches $4000 \mathrm{~kg}$, the melting power was switched off for 5 min, then restarted the arc to continue the remelting process with the same melting rate. After hot topping and cooling, the ingot was cut from the location $300 \mathrm{~mm}$ above the liquidus line of melting interruption. The sample with a length of $1200 \mathrm{~mm}$ was cross-sectioned longitudinally from the center line for grinding and metallographic analysis. The cross section was etched for 15-20 seconds using a $\mathrm{HF}-\mathrm{HNO}_{3}-\mathrm{H}_{2} \mathrm{O}$ solution with volume ratio of 1:3:7. After etching, at intervals of 150 mm of the total sample length, samples at ingot center, 1/4R, 1/2R and edge were prepared for ICP chemical composition analysis to show possible composition changes across the interrupted region and normal regions. Metallographic samples with a dimension of $40 \times 20 \times 20 \mathrm{~mm}$ were cut in the melting interruption region and normal solidification region for detailed microstructure analysis. The microstructure etching solution is standard $\mathrm{Kroll}$ 's reagent, $\mathrm{HF}^{-} \mathrm{HNO} \mathrm{O}_{2} \mathrm{O}$ solution with a volume ratio of 1:2:47, the etching time is $4 \sim 8$ seconds. Olympus BX51M optical microscope (OM) was used to analyze the microstructures. EPMA was used to analyze and compare the microscopic distribution of elements within the equiaxed grains in the melting interrupted region and normal solidification regions.

\section{$\underline{\text { 3. Results and Discussion }}$}

3.1 Macrostructure characterization of BT22 ingot

(C) The Authors, published by EDP Sciences. This is an open access article distributed under the terms of the Creative Commons Attribution License 4.0 (http://creativecommons.org/licenses/by/4.0/). 
Figure 1 shows the macrostructure of the ingot, defining the original cut location as $0 \mathrm{~mm}$, and the other end as $1200 \mathrm{~mm}$. As shown in Figure 1 , the location of melting interruption region is at $300 \mathrm{~mm}$, and the area of 300 to $900 \mathrm{~mm}$ is the molten pool. The depth of the molten pool at the melting interruptted region is approximately $600 \mathrm{~mm}$, as determined by simulation using Meltfow. The area of 900 to $1200 \mathrm{~mm}$ is the solidified part before the interruption.

Figure 1 also shows no significant difference in the grain size distribution between the melting interruption region and the normal solidified regions. The ingot has columnar grains at the edges, and the columnar grain region increases gradually from the top to the bottom, as indicated by the yellow dashed lines in Figure 1. The thickness of columnar-grained region is approximately $200 \mathrm{~mm}$, and the orientation of columnar grain is approximately $35^{\circ}$ deviated from the horizontal direction. The axial center region of the ingot has small equiaxed grains, with an average grain size of $6 \mathrm{~mm}$. The maximum diameter of the equiaxed grain region is nearly $180 \mathrm{~mm}$. It is also noticed that there is a transition region between the equiaxed grain and the columnar grain regions. The grains in the transition region are equiaxed and has an average grain size of about $10 \mathrm{~mm}$. The thickness of the transition region varies between 30 to 50 $\mathrm{mm}$. Variation of grains size in the transition region is smaller at normal solidification areas compared to the interrupted region. 


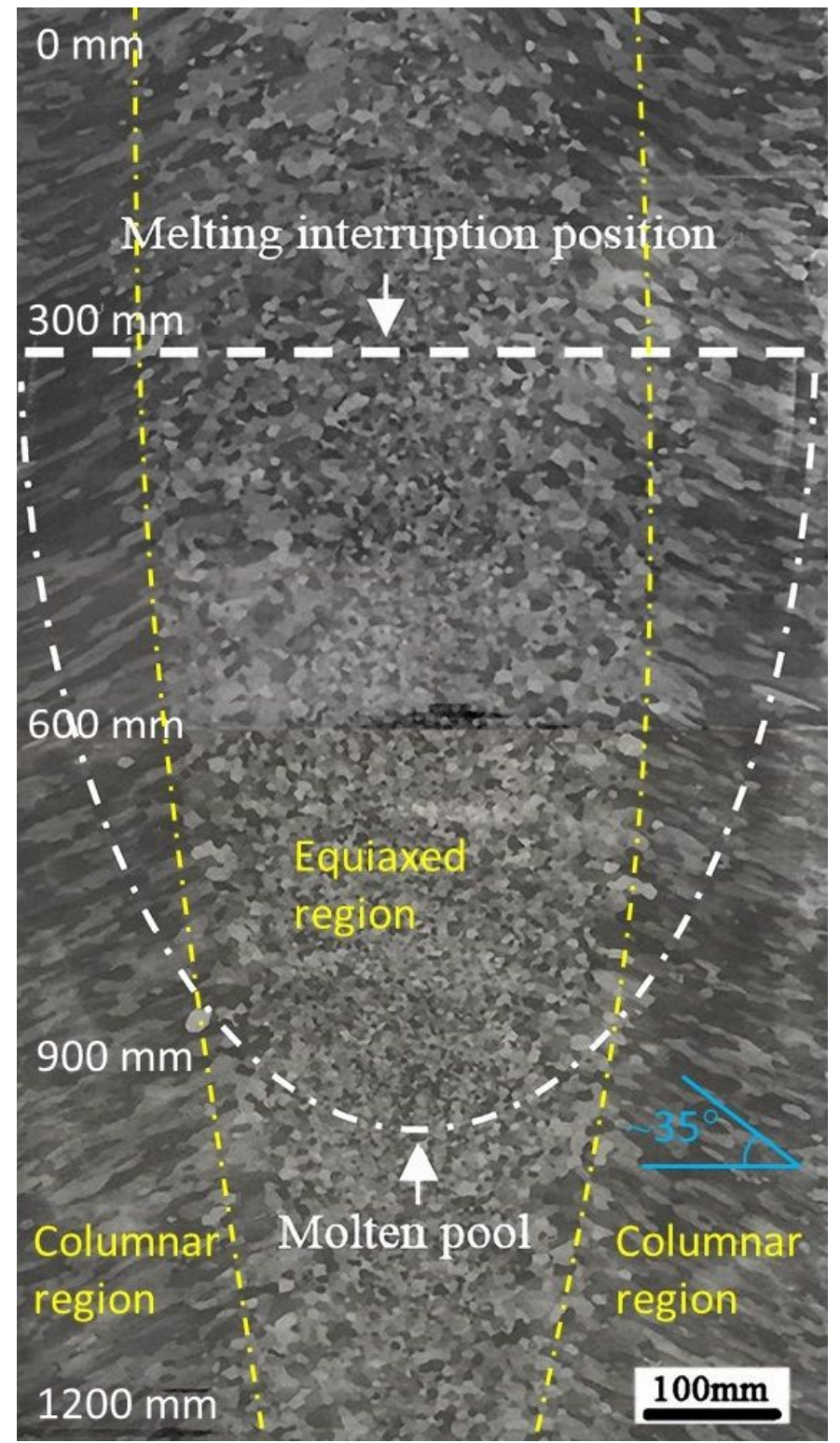

Figure 1 Macrostructure of BT22 ingot centerline

Due to the large temperature gradient within the molten pool, as well as between the molten pool and the crucible, the columnar-grained region of the ingot exhibits a specified orientation. The growth direction of the columnar grains is about $35^{\circ}$ to the horizontal. The length and width of a single columnar grain is about $100 \mathrm{~mm}$ and $10 \mathrm{~mm}$, respectively. The size of prior- $\beta$ grains (entire width of columnar) is about $80 \mathrm{~mm}$. Solidication speed decreases with the decreasing of temperature gradient, which makes the transformation of the columnar grain to equiaxed grain easy to occur. In the progress of solidification, the temperature gradient decreases gradually near the center of the ingot. At this time, the solidified region exhibits a region with mixed smaller columnar grains and equiaxed grains. With the further reduction of solidification temperature gradient, the temperature gradient in the center of the ingot reaches a 
constant, resulting in a region of equiaxed grain in the center. During the interruption of the melting, the direction of the temperature gradient did not change significantly, so the direction of macroscopic grain growth of the ingot remains same as that of the normal solidication regions.

\subsection{Macroscopic composition analysis of BT22 ingot}

The element distributions of the interrupted region and the normal regions of the ingot are shown in Figure2.
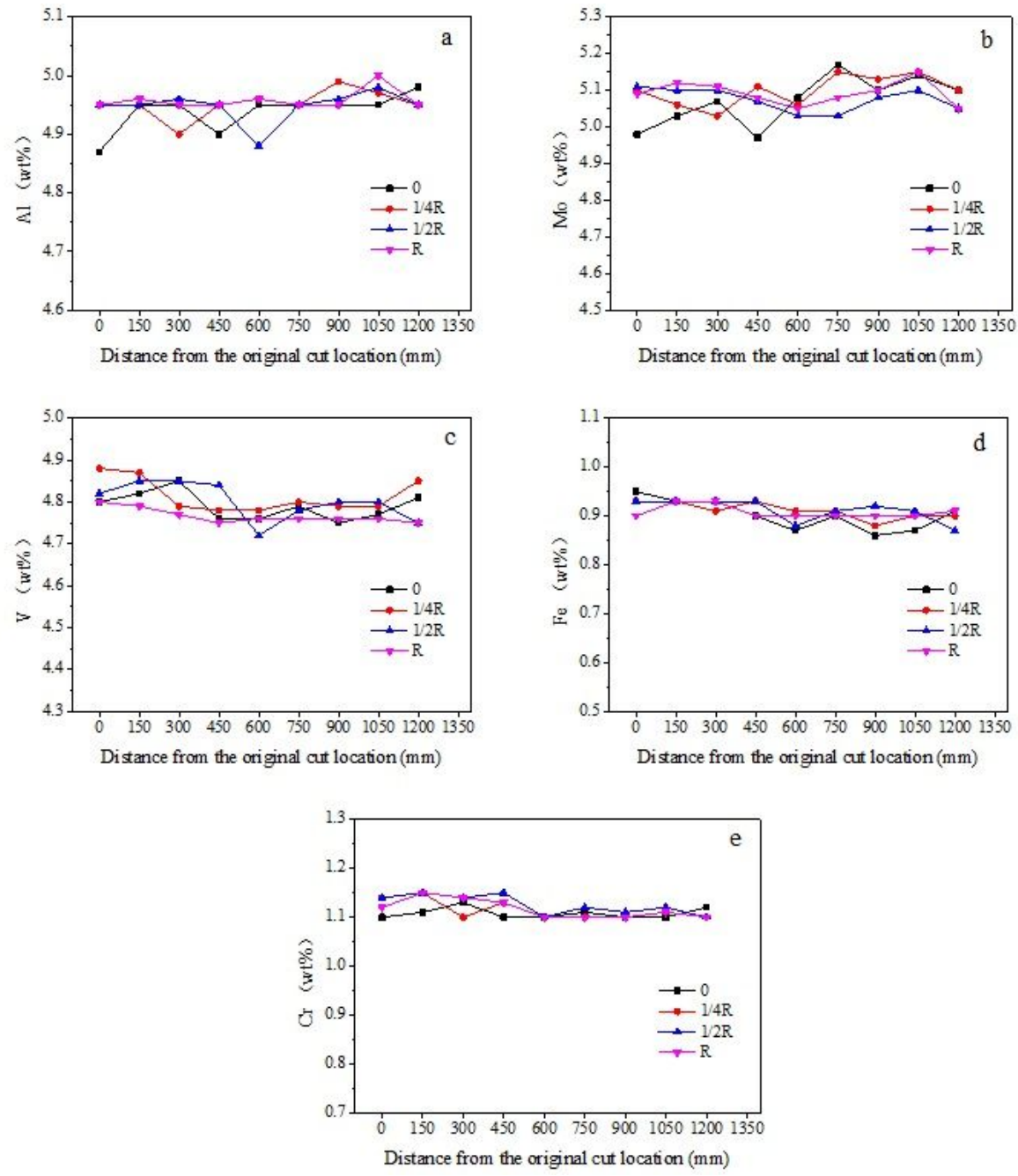

Figure 2 Macrocomposition distribution of BT22 ingot, a. Al, b. Mo, c. V, d. Fe, e. Cr.

samples at ingot center(0), 1/4R, 1/2R and edge( $R)$

Higher content fluctuation of $\mathrm{Al}$, Mo and $\mathrm{V}$ was observed compared to $\mathrm{Fe}$ and $\mathrm{Cr}$. The maximum $\mathrm{Al}$ content of 5.00 wt $\%$ was found at the edge of the ingot near the bottom $(1200 \mathrm{~mm}$ ), while the minimum content of $4.83 \mathrm{wt} \%$ was at the top part of the center, the variation is $0.17 \mathrm{wt} \%$. For Mo, the content at the edge of the ingot and the $\mathrm{R} / 2$ axis is relatively stable, the variation of Mo elements on the edge axis is only $0.10 \mathrm{wt} \%$. Greater fluctuation of Mo was 
seen near the centerline of the ingot, and the centerline region has the maximum Mo content variation. The range between maximum and minimum values is $0.23 \mathrm{wt} \%$. Higher content fluctuation of $\mathrm{V}$ was detected in the region of $0 \mathrm{~mm}$ to $600 \mathrm{~mm}$, with a content fluctuation of $0.17 \mathrm{wt} \%$. While the fluctuation is $0.13 \mathrm{wt} \%$ in the area between $600 \mathrm{~mm}$ to $1200 \mathrm{~mm}$. For Fe element, the fluctuation range of Fe element content in the center of the ingot is obviously larger than that of the $\mathrm{Fe}$ element in the edge of the ingot, the variation at the center axis $\mathrm{Fe}$ is $0.09 \mathrm{wt} \%$. The content range of $\mathrm{Fe}$ at $\mathrm{R} / 4$ and $\mathrm{R} / 2$ is 0.05 $\mathrm{wt} \%$. The Fe content range at centerline is only $0.03 \mathrm{wt} \%$. The content variation of $\mathrm{Fe}$ at different depths is smaller than that in the radial direction. For the Cr element, the range is $0.05 \mathrm{wt} \%$ in the area from $0 \mathrm{~mm}$ to $600 \mathrm{~mm} .0 .02 \mathrm{wt} \%$ Fluctuation of $\mathrm{Cr}$ content was found in the range of $600 \mathrm{~mm}$ to $1200 \mathrm{~mm}$. The overall distribution of elements is uniform.

The results of composition analysis show that the distribution and fluctuation of the elements are similar between the normal solidified region and the 5 minutes power interrupted region. The melting interruption has no obvious effect on the macroscopic composition of the ingot.

3.3 Microstructure of the BT22 ingot
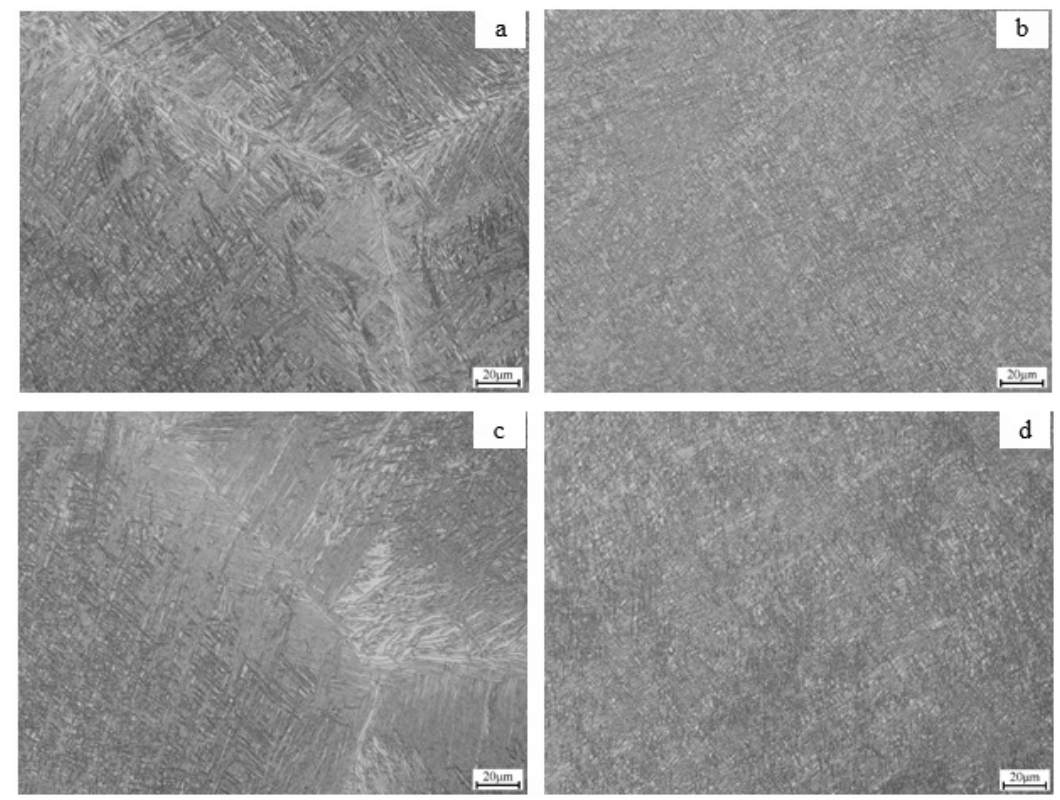

Figure 3 Microstructure of equiaxed grains a. grain boundary of melting intrruptted region, b. grain center of melting interrupted region, c. grain boundary of normal region and d. grain center of normal region.

Figure 3a and Figure $3 \mathrm{~b}$ show the microstructure of equiaxed grain boundaries and grain center, respectively, at the melting interrupted region. Figures $3 \mathrm{c}$ and $3 \mathrm{~d}$ show the microstructures of equiaxed grain boundaries and grain center of a normal region. It is shown that $\alpha$ phase in the prior- $\beta$ grains near grain boundaries is mainly in the form of neatly arranged fine lamellars. The equiaxed grains are composed of ultra-fine basketweave $\beta$ transformed microstructure. The length of the acicular $\alpha$ grains within the equiaxed prior- $\beta$ grains ranges from 10 to $30 \mu \mathrm{m}$, and their width ranges from 1 to $3 \mu \mathrm{m}$. No obvious difference in grain morphology was observed between the melting interrupted and normal regions.

\subsection{Microcomponent analysis of BT22 ingot}

In order to clarify the effect of melting interruption on microcomposition of the ingot, two adjacent equiaxed grains with a grain size of about $10 \mathrm{~mm}$ were selected in the melting interruption region and normal region, as shown in Figure $4 \mathrm{a}$ and Figure 4b, for EPMA analysis. EPMA analysis was performed to test the local composition of every $1 \mathrm{~mm}$ from the center of the first grain to the center of the second grain, as shown in the schematic in Figure 5. The average values of three sets of test data were ploted and shown in Figure 6. 

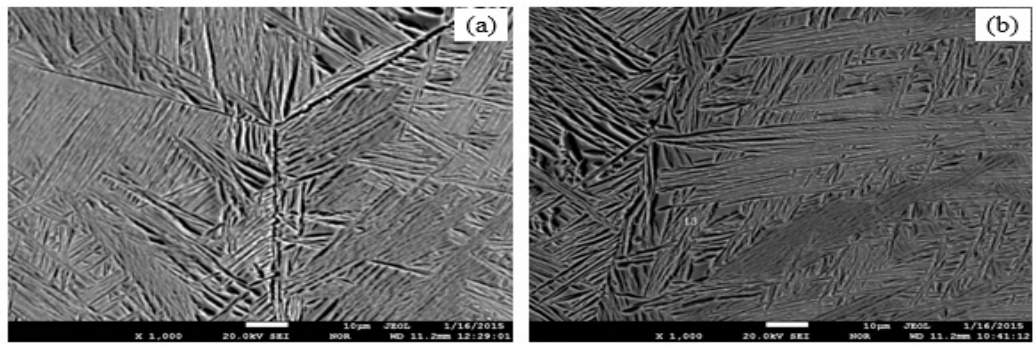

Figure 4 Regions for EPMA analysis of equiaxed grains, a. interrupted region, b. normal region.

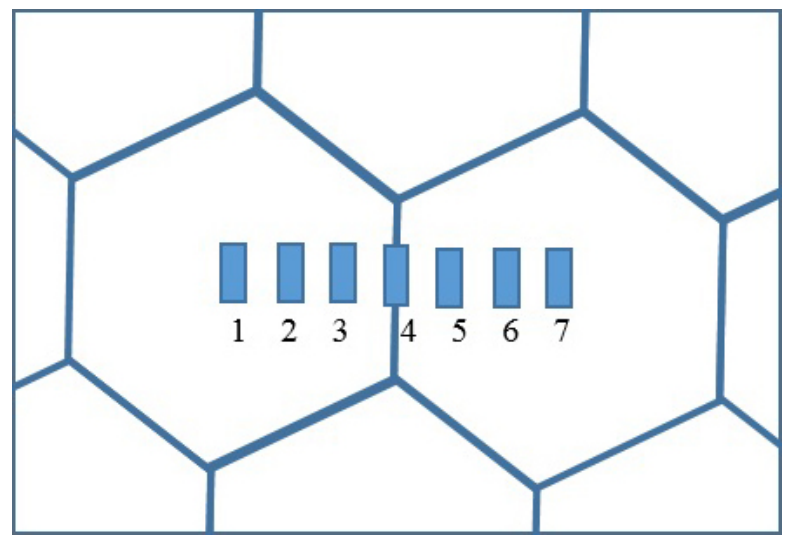

Figure 5 Schematic of locations for EPMA analysis

It can be seen from the Figure 6 that the grain boundary has $0.1 \mathrm{wt} \%$ higher $\mathrm{Al}$ content compared to the center of equiaxed grains, in contrats, the $\mathrm{Al}$ content range between grain boundary and grain center for normal regions is $0.21 \mathrm{wt} \%$. The $\mathrm{Cr}$ content also increases in the equiaxed grain growth direction. The $\mathrm{Cr}$ content range between grain boundary and inside is $0.13 \mathrm{wt} \%$ at the power interrupted region. The range for the normal regions is 0.23 $\mathrm{wt} \%$. The Mo element has the opposite trend. The content of the Mo element decreases in the direction of equiaxed grain growth. The content vairation of Mo content between grain boundary and inside, in the power-interrupted region, is $0.31 \mathrm{wt} \%$, which is similar to that of the normal region $(0.32 \mathrm{wt} \%)$. The content of $\mathrm{V}$ and $\mathrm{Fe}$ increases along the growth direction of equiaxed grains. The variation of $\mathrm{V}$ content between the grain boundary and the inside of the grain in the interrupted region is $0.25 \mathrm{wt} \%$, and this value is $0.16 \mathrm{wt} \%$ in the normal region. The variation of Fe content between the grain boundary and the inside of the grain in the interrupted region is $0.17 \mathrm{wt} \%$, and such value is $0.15 \mathrm{wt} \%$ in the normal region. 

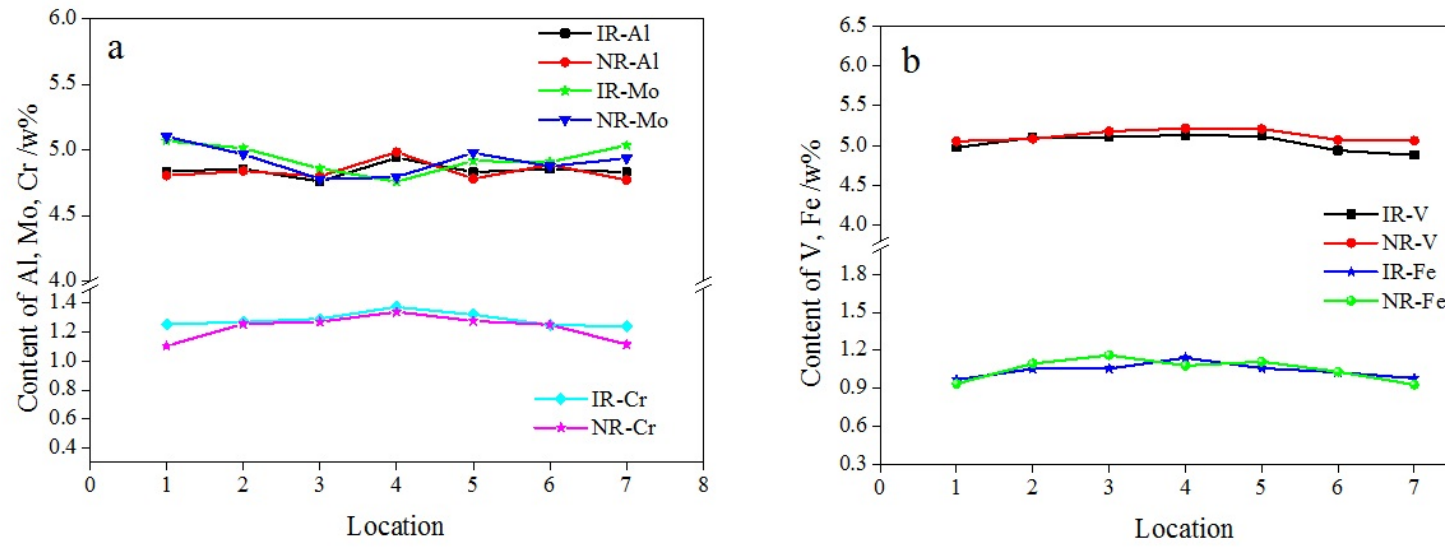

Figure 6 Microcomponents of EPMA in equiaxed grains, a. content of Al, Mo Cr, b. content of V, Fe.

\section{IR: the interrupted region, NR: the normal region.}

As has been known, the solute redistribution occurs in the solid-liquid front during solidification ${ }^{[5]}$. The solute redistribution coefficient $\mathrm{k}_{0}=\mathrm{Cs}^{*} / \mathrm{C}_{1}{ }^{*}$, where $\mathrm{Cs}^{*}$ is the solute content of solid phase at the front of solid solution, $\mathrm{C}_{1} *$ is the solute content of the liquid phase at the front of solid solution. When $\mathrm{k}_{0}<1$, the solid phase at the solidification front continuously precipitates solute atoms into the liquid phase, resulting in enrichment of solute elements in the liquid phase. When $\mathrm{k}_{0}>1$, the opposite trend occurs, according to Ti-Al, Ti-Mo, Ti-V., Ti-Cr, Ti-Fe binary phase diagram ${ }^{[6]}$, the partition coefficient of Al, $\mathrm{V}, \mathrm{Fe}, \mathrm{Cr}$ solute is less than 1 , Mo element solute partition coefficient is greater than 1 . Thus in the radial direction (grain growth direction) of equiaxed grains, the contents of $\mathrm{Al}, \mathrm{V}, \mathrm{Fe}$ and $\mathrm{Cr}$ increase gradually, but the content of Mo decreases.

\section{Conclusion}

1) At the melting rate of $20 \mathrm{~kg} / \mathrm{min}, 5$ minutes of power interruption does not cuase significant change of the shape of the columnar grain and the equiaxed grain growth of the ingot. The corresponding morphology of the mushy zone does not change significantly either.

2) Even thorugh there is a certain fluctuation of element content, the melting interruption has no obvious influence on the macroscopic composition of the ingot. In the radial direction of the ingot, the element distribution is more homogeneious.

3) No obvious difference in microstructure was observed between the interruption region and the normal regions. The $\alpha$ phase in the prior- $\beta$ grains near grain boundary is mainly in the form of irregular lamellar microstructure. The equiaxed grains are composed of ultra-fine basketweave $\beta$ transformed microstructure.

4) The contents of $\mathrm{Al}, \mathrm{V}, \mathrm{Fe}$ and $\mathrm{Cr}$ increase in the radial direction of the equiaxed grains. Mo content has the opposite trend. The distribution trend of elements in the normal region is consistent with those of the power-interrupted region.

\section{$\underline{\text { 5. References }}$}

[1] Mitchell A. Melting, Casting and Forging Problems inTitanium Alloys[J]. Mater Sci Eng A, 1998, 243-257.

[2] Zhou Yiaohe, Hu Zhuangqi, Jie Wanqi. Consolidation Technology[M]. Beijing:Machinery Industry Press, 1998, 56-58.

[3] Dou Yongqing. Distribution of main alloying elements of titanium alloy in ingots[J].The 6th National Titanium and Titanium Alloy Academic Exchange Conference.Beijing: Atomic Energy Press 1987,43-48. 
[4] Zhao Yongqing,Liu Junlin,Zhou Lian, Analysis on the Segregation of Typical $\beta$ Alloying Elements of Cu, Fe and Cr in Ti Alloys[J].Rare metal materials and engineering,2005,34(4):531.

[5] Kurz W,Fisher D J,Fundamentals of solidification[M]. 2th ed.Switzerland: Trans. Tech. Publications, 1989:48.

[6] Tiller W A,Jackson K A,Rutter J W,Chalmers B The redistribution of solute atoms during the solidification of metals[J]. Acta Metallurgica, 1953, $1: 428-437$ 